\title{
Configurações
}

Revista de sociologia

\section{Divisão sexual do trabalho doméstico: entre representações e práticas}

Sexual division of housework: between representations and practices

Division sexuelle du travail domestique : entre représentations et pratiques

Manuel Carlos Silva, Ana Reis Jorge e Aleksandra Queiroz

\section{(2) OpenEdition \\ Journals}

\section{Edição electrónica}

URL: http://journals.openedition.org/configuracoes/1158

DOI: 10.4000/configuracoes. 1158

ISSN: 2182-7419

\section{Editora}

Centro de Investigação em Ciências Sociais

\section{Edição impressa}

Data de publição: 30 Junho 2012

Paginação: 135-159

ISSN: 1646-5075

\section{Refêrencia eletrónica}

Manuel Carlos Silva, Ana Reis Jorge e Aleksandra Queiroz, « Divisão sexual do trabalho doméstico: entre representações e práticas », Configurações [Online], 9 | 2012, posto online no dia 27 novembro 2013, consultado o 19 abril 2019. URL : http://journals.openedition.org/configuracoes/1158 ; DOI : 10.4000/configuracoes. 1158

Este documento foi criado de forma automática no dia 19 Abril 2019.

(c) CICS 


\section{Divisão sexual do trabalho doméstico: entre representações e práticas}

Sexual division of housework: between representations and practices

Division sexuelle du travail domestique : entre représentations et pratiques

Manuel Carlos Silva, Ana Reis Jorge and Aleksandra Queiroz

\section{Introdução: o problema e método}

1 São hoje amplamente (re)conhecidos em Portugal diversos e aprofundados estudos sobre a família, para o qual têm contribuído diversos cientistas sociais. Relativamente à questão da divisão sexual do trabalho, deverão, contudo, ser destacadas as recentes investigações coordenadas por Karin Wall (2005) e por Karin Wall e Lígia Amâncio (2007) que, afirmando o crescendo de uma tendência para atitudes mais igualitárias nas últimas décadas ao nível do trabalho, quer pago, quer não pago, não deixam de relevar tanto a diversidade e as assimetrias face a outros países europeus, quanto a especificidade do caso português, no qual se combinam, a este nível, aspectos de cariz moderno e tradicional.

2 Tal como refere Treas (2010:14), "o trabalho doméstico permanece um lugar estratégico para o estudo das desigualdades de género". Este texto incide sobre a divisão das tarefas domésticas entre homens e mulheres em união de facto ou casamento heterossexual, não só revelando as suas concepções a este respeito como confrontando as representações com as práticas sociais nesta matéria, aferindo o grau de discrepância entre as mesmas.

Começando por problematizar os diversos posicionamentos relativos ao tópico em discussão, o texto tem por base dados empíricos recolhidos a partir de uma investigação centrada nas (des)igualdades de género, no âmbito da qual foi aplicado um inquérito, com base numa amostra por quotas, a 802 pessoas em Portugal Continental distribuídas por sexo, idade, profissão, tipo de residência (rural ou urbano), activo-não activo ${ }^{1}$. Atendendo à temática, importa notar que, no seio da amostra, tomámos em conta os inquiridos que 
afirmaram ser casados/viver em união de facto. Além do inquérito, foram ainda realizadas 40 entrevistas.

4 Os resultados recolhidos confirmam conclusões de outros trabalhos nacionais e internacionais: não obstante, a nível das representações, se esboçar uma tendência no sentido de partilha das tarefas duma forma equitativa, persistem a desigualdade entre homem e mulher em desfavor desta na distribuição das tarefas domésticas e respectivas horas semanais despendidas. Como veremos, verificam-se a este nível variações atendendo a outras variáveis, tais como a pertença profissional e o escalão etário.

Uma das bases explicativas do diferente lugar ocupado pelo homem e pela mulher residiria na divisão sexual do trabalho, a qual, segundo Engels (1980), estaria inclusive na base da propriedade privada e do nascimento do Estado.

6 Sem entrarmos aprofundadamente neste debate, é de relevar que estudos sobre diversos tipos de sociedades, nomeadamente industriais, sustentam que a mulher, quando confinada exclusivamente às tarefas de casa e aos cuidados com os filhos, tende a ver reduzido - e amiúde subvalorizado - o seu papel em termos económicos, bem como a perder espaço de intervenção e decisão nas esferas social, política e cultural. Contrariamente ao trabalho de produção por parte do homem no exterior, que lhe confere uma parcela, maior ou menor, de poder e capacidade de decisão na casa, o trabalho doméstico é tido por periférico e banal, não valorizado e, como tal, tão pouco remunerado. Tal situação recoloca o problema da dicotomia de género e consequente desigualdade entre o trabalho doméstico e o extradoméstico, visível no volume de remuneração e no grau de prestígio. Mais, apesar de cada vez mais a mulher acumular trabalho extradoméstico e doméstico, o seu poder e capacidade de decisão no próprio espaço doméstico não aumenta, comportando ainda assimetrias de género ${ }^{2}$. Assim, desde logo emergem algumas questões: Quais as representações sobre o trabalho doméstico por homens e mulheres e donde vêm tais representações? Há discrepância entre representações e práticas e, em caso afirmativo, como se explica tal discrepância?

7 Antes de darmos algumas pistas de resposta com base nos resultados empíricos, faremos um breve enquadramento sociológico sobre o conceito de representação social e breve revisitação teórica em torno das práticas inigualitárias de género na família.

\section{Representações sociais e práticas: breve enquadramento sociológico}

8 O conceito de representação social remete para imagens e sistemas de referência, formas de reprodução e categorização do pensamento em relação à realidade social com o objectivo de a compreender, interpretar e/ou explicar ou ainda para a classificar e/ou mesmo justificar ou contestar. Neste sentido a noção de representação não é unívoca, mas antes polissémica e detém uma diferenciada densidade explicativa em relação à realidade social, o que é visível nas diferentes interpretações e força heurística e explicativa dada pelos vários fundadores da Sociologia e respectivas correntes de pensamento.

9 Assim, começando por Durkheim (1974), as representações sociais, embora estejam ligadas a outros factos sociais e sejam elas próprias factos sociais, não são nem ideias inatas nem preexistentes nos indivíduos, à boa maneira kantiana, mas possuem determinadas propriedades inerentes à sociedade e universalmente consubstanciadas na designada consciência colectiva. Ou seja, enquanto elemento constituinte e determinante 
da realidade social, elas estruturam-se independentemente dos indivíduos e surgem a partir da sociedade para, seguidamente, se reproduzirem através do longo processo de socialização, posição esta partilhada por Parsons (1956), segundo o qual o homem deteria na família a função instrumental enquanto provedor e a mulher a função expressiva, ambas perspectivadas em termos de complementaridade e equilíbrio funcional. Em suma, as representações sociais, designadamente em torno da família e do género, integram-se na definição geral dos factos sociais enquanto "maneiras de pensar, sentir e agir, exteriores ao indivíduo e dotadas de um poder imperativo e coercitivo em virtude do qual se lhes impõem" (Durkheim 1974: 34).

Numa perspectiva oposta e até antagónica se situa a perspectiva marxista, segundo a qual as representações sociais pertencem à esfera do superestrutural e, como tal, são produtos ou elementos derivados da infraestrutura, com a particularidade de veicularem amiúde as ideias ou ideologias das classes dominantes expressas na arte e na cultura, na moral e na religião, na filosofia ou na política, entre outras (Marx e Engels 1976). É o ser social que determina a consciência e não o contrário. As representações sociais, ideias e concepções presentes na consciência, assim como as ideologias só se poderão entender e explicar a partir da sua base material económica, do lugar objectivo das classes e dos indivíduos na vida económica e social. Releve-se, porém, que certos excertos de Marx e posições de Lukács (1967), Gramsci (1974) e Lefebvre (1977) e vários (neo) marxistas se afastam de uma abordagem monocausal, economicista ou mecânica, realçando a importância da consciência, da linguagem, dos processos de hegemonia e/ou, em contraponto com o racionalismo, revalorizando e contextualizando o senso comum não só em termos de conservação mas também de luta na vida quotidiana, na mudança e na emancipação.

11 Numa perspectiva intermédia e plural podemos enquadrar a abordagem weberiana (1990). O conceito de representação é traduzido por ideia, concepção, mundividência ( Weltanschauwung), a qual, comportando juízo de valor, correlaciona-se com a base económica material, a vida mundana e dos interesses, mas não é, contrariamente à visão corrente do marxismo, um simples reflexo desta mas um factor culturalmente significativo, relativamente autónomo e indutor de efeitos próprios. ${ }^{3}$

Num entendimento próximo ou convergente com a posição weberiana situa-se a perspectiva quer de Simmel (1977) quer, de certa maneira, Mead (1934) e Goffman (1989), numa abordagem interaccionista, e Schutz (1993) numa perspectiva fenomenológica. Estas correntes dão especial relevo às interacções e representações do 'senso comum' na vida quotidiana, ou seja, às capacidades de negociação, aos significados e às interpretações que os actores fazem das experiências no dia-a-dia.

13 Apesar de Weber $(1978,1990)$ se distanciar da interpretação marxista, não descura a ligação das concepções, culturas e mundividências com os respectivos interesses das classes/grupos sociais, designadamente em situação de poder e, nesta óptica, há elementos de continuidade com a perspectiva marxista. Foi aliás nesta base de recuperação dialética da perspectiva marxista e weberiana que Bourdieu (1989) veio relevar a ideia nuclear da representação e do sistema simbólico como produto (opus operatum), no sentido marxista, mas igualmente como mecanismo produtor numa perspectiva mais weberiana (modus operandi), ambos mediados pelo habitus, enquanto sistema de disposições integrador das experiências passadas mas também como matriz de percepções e acções presentes ou futuras.

14 O tema das representações sociais tem vindo a ser particularmente desenvolvido teórica e empiricamente por psicólogos sociais, sendo de referir como incontornável o legado de 
Moscovici (1989), segundo o qual as representações sociais compreendem formas de conhecimento socialmente partilhado, provindo da conjugação das formas da realidade social e da construção e interpretação da mesma pelos próprios indivíduos e grupos sociais. ${ }^{4}$

No nosso entender, as representações e mesmo as ideologias não podem ser desligadas das condições de vida objectiva em termos de pertença de género, de classe e, em particular, a fonte de rendimento, os processos de socialização e as correlativas atitudes e preferências inculcadas, mas, tal como o apontam Crompton et al (2005), a ideologia conta cada vez menos nas decisões dos próprios actores sobre determinadas questões domésticas, uns com maior, outros com menor grau de autonomia. No caso em estudo, a própria reprodução e persistência de determinadas representações sociais, nomeadamente por parte das mulheres, no sentido da aceitação das assimetrias de género na distribuição das tarefas domésticas prende-se amiúde não só com o seu afastamento do processo produtivo e dos demais recursos externos como com o grau, maior ou menor, de subordinação ideológica, a qual, por sua vez, se articula, numa perspectiva weberiana (Weber 1978), com o diferenciado grau de capacidade negocial e sobretudo de poder de disposição sobre recursos, traduzindo amiúde, como refere Bourdieu (1989), formas de dominação masculina. Nesta óptica, importa distinguir até que ponto a ideologia da subordinação sexual vai ou não de par, como refere Dubisch (1986:21), com o efectivo controlo sobre recursos e a capacidade de decisão. Tal inclui, além do domínio sobre a força de trabalho e alheia - quando presente ou convocada -, a planificação e a execução de actividades domésticas e repercute-se em assuntos tais como a procriação e a educação dos filhos, as opções matrimoniais e profissionais destes ou a devolução dos bens. Por outro lado, o facto de as representações e práticas sociais em torno da divisão sexual das actividades domésticas constituírem o objecto central deste texto não pode obnubilar que nos grupos domésticos se articulam os níveis micro e macro, sendo co-estruturados por impactos nacionais e internacionais, designadamente vectores (macro)económicos da sociedade global e determinações institucionais designadamente estatais na esfera simbólica e político-jurídica (cf. Pinto 1985: 120 ss, Santos 1990: 23 ss, Silva 1991, Treas 2010, Sayer 2010). Com efeito, com a inequívoca presença maciça das mulheres no contexto do trabalho remunerado verifica-se, como refere Drobnic (2010:241), uma alteração de papéis de género, sendo bem mais evidente no caso das mulheres que dos homens, cujo envolvimento nas tarefas de produção doméstica é ainda incipiente e/ou selectiva, embora cada vez maior num quadro de negociação de papéis e distribuição de tarefas na esfera doméstica. ${ }^{5}$

As desigualdades na repartição de tarefas entre homens e mulheres, bem como de suas respectivas práticas são diferentemente interpretadas. Certos autores como Pfau-Effinger (2010) relacionam os padrões inigualitários de género no trabalho doméstico com diferentes esquemas culturais ('cultura servil' nos países do sul versus culturas igualitárias em países nórdicos) ou a determinadas crenças ou ideologias em torno de determinados valores institucionais como o da maternidade (Charles e Cech 2010) ou do casamento. Com efeito, os valores culturais familistas em torno da maternidade no sul da Europa implicariam uma dedicação plena das mães em contexto familiar (Pfau-Effi nger et al 2010). Por sua vez, é relevado por Yodanis (2010) o valor psico-cultural da intimidade e comunicação conjugal como factores estruturantes do sucesso matrimonial e duma distribuição mais igualitária do trabalho doméstico, do mesmo modo que, segundo a tipologia de Rohler e Huinink (2010: 199 ss) inspirada no pensamento weberiano, os 
diversos tipos de modelos ideais de conjugalidade e respectivas relações afectivas marcam de modo diferenciado a divisão sexual do trabalho entre cônjuges: fortemente desigual no tipo de relações afectivas tradicionais, ${ }^{6}$ tendencialmente igual na partilha de tarefas nas relações afectivas associativas e variável conforme preferências mas insensível à igualdade em relações afectivas pragmáticas em contextos altamente individualizados.

Outros autores relevam os tipos de regimes de Estado social relativamente às políticas de família e cuidado dos filhos, possibilitando inclusive a formação de outras visões culturais sobre a família, maternidade e cuidado dos filhos, tal como o evidenciaram respectivamente, entre outros, Geist (2005), Esping-Andersen (2009), Treas e Drobnic (2010). ${ }^{7}$ Ou seja, de acordo com esta perspectiva político institucional, os diferentes arranjos e impactos na distribuição das tarefas domésticas por género sofrem a forte influência dos respectivos regimes de protecção social. Assim, enquanto os regimes conservadores dão prioridade à maternidade num contexto de dependência económica da mulher, reproduzindo o esquema convencional parsoniano e estimulando a responsabilidade e atribuição à mulher de tarefas domésticas e cuidados dos filhos, o regime liberal realça a liberdade individual e orienta-se para o mercado e correlativa prestação de serviços, o regime social-democrata sublinha os princípios da igualdade, a desmercantilização, a desfamiliarização, o apoio estatal aos filhos e, consequentemente, liberta a mulher de horas de trabalho doméstico em benefício de trabalho extradoméstico pago (cf. Esping-Andersen 2009, Van der Lippe 2010, Sayer 2010, Drobnic 2010). Por sua vez, tal como o evidenciaram Cooke (2010) e Dex (2010), as políticas estatais designadamente educativa e fiscal, a legislação laboral e sobretudo a política de família condicionam o tempo de trabalho doméstico e extradoméstico para homens e mulheres.

\section{Divisão sexual de tarefas domésticas: entre representações e práticas}

18 Se a divisão do trabalho doméstico constitui uma matéria problemática e sensível, importa aferir as representações dos inquiridos, materializadas na concepção relativa à forma ideal de divisão do trabalho doméstico, por sexo, o que nos é dado pela figura 1. 
Figura 1. Forma ideal de divisão do trabalho doméstico, por sexo (\%)

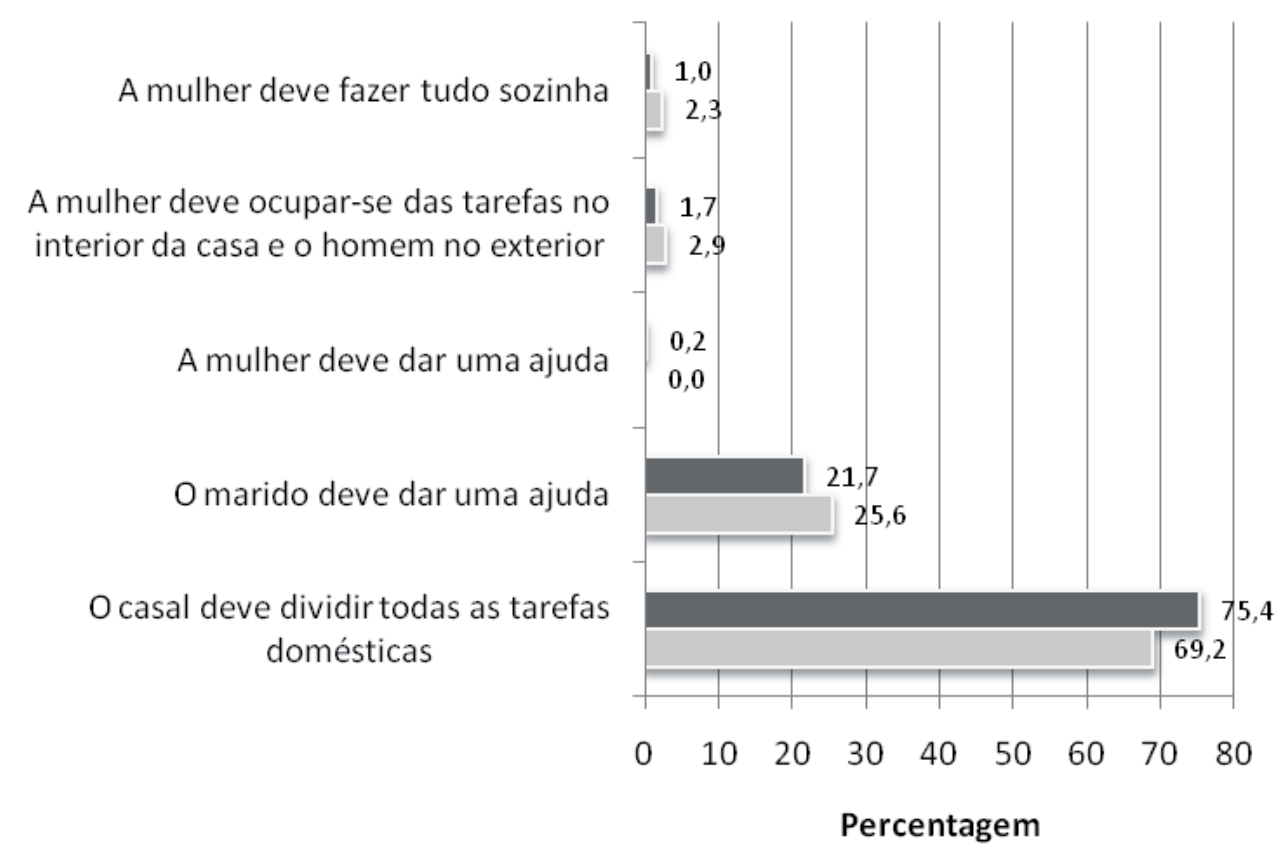

Mulheres Homens

Fonte: Inquérito sobre Desigualdades de Género (IDG), 2011; N=802 inquiridos, em quase todos os níveis de escolaridade (entre 54,9\% e 88,5\%), também a concepção de que "o casal deve dividir todas as tarefas domésticas". Este posicionamento é mais acentuado entre os/as inquiridos/as com habilitações relativamente elevadas (desde os 3.․ ciclo até curso superior) e menos expressivo nos grupos menos escolarizados ( $1^{\circ}$ ciclo do ensino básico ou escolaridade inferior). Em suma, há uma correlação proporcional entre habilitação e representação democrática da repartição de tarefas domésticas, o que, à luz das representações ou mesmo da retórica da igualdade de género, os mais habilitados têm capacidade de exprimir-se conforme a norma politicamente correcta. Não raro, porém, este princípio é derrogado nas práticas sociais, remetendo o 
grosso das tarefas domésticas para a mulher com o eventual efeito de diminuição de horas e salário no trabalho pago extradoméstico ${ }^{8}$; ou, então, o problema é contornado, sempre que o casal tem capacidade económica de transferir, contratando, para uma empregada doméstica a grande parte das tarefas caseiras e mesmo o cuidado quotidiano com os filhos. ${ }^{9}$

Se ao nível dos valores se verifica alguma aproximação entre homens e mulheres, no que concerne a divisão do trabalho doméstico são já notórias algumas diferenças pautadas pela variável sexo, pese embora a tendência geral, na subamostra de casados e unidos de facto, de os inquiridos/as responderem que as diversas tarefas são divididas entre os membros do casal $(63,1 \%)$. A informação da figura 2 dá conta das diferenças consoante o sexo.

Figura 2. Grau de participação na divisão do trabalho doméstico no casamento, por sexo (\%)

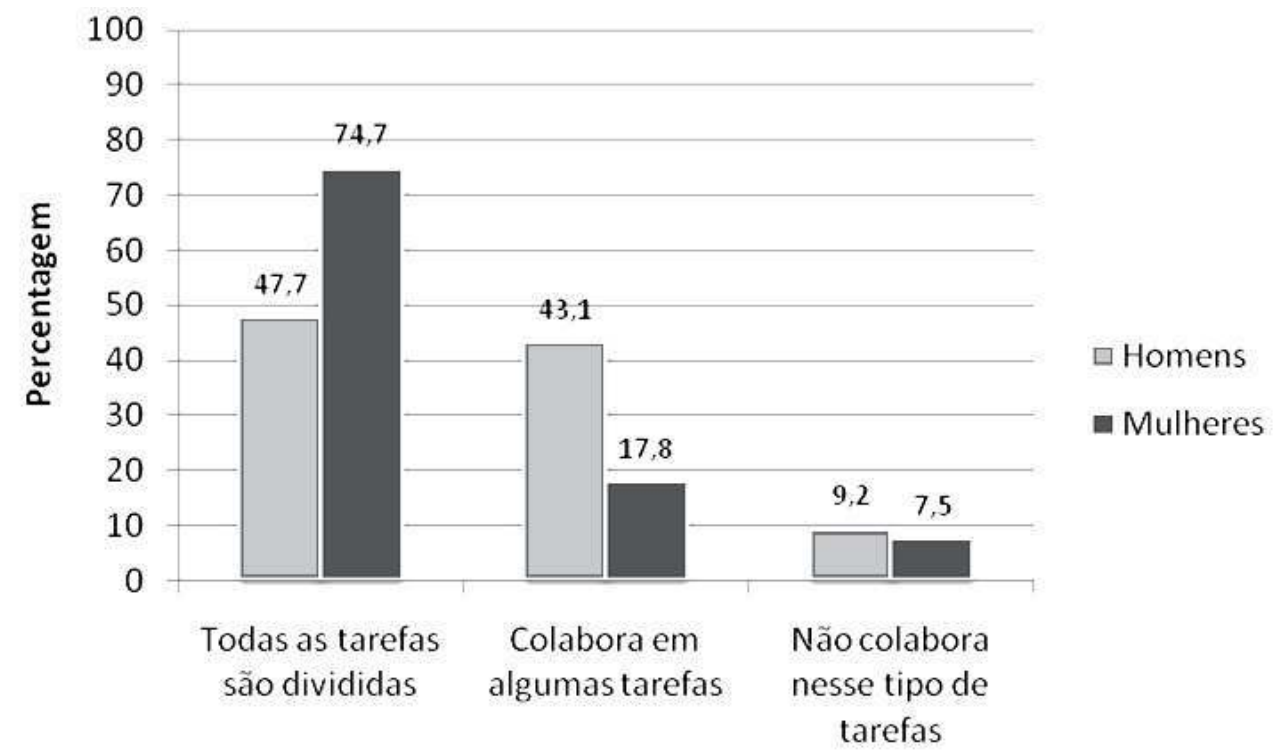

FONTE: IDG, 2011; N=559

Efectivamente, a figura 2 sugere que a forma de divisão do trabalho doméstico não é independente do sexo. Por um lado, existem significativamente mais mulheres que homens a mencionar que "todas as tarefas são divididas" ( $74,7 \%$ vs. $47,7 \%)$, o que surpreende, a não ser que as mulheres registem o facto de haver divisão de tarefas sem referência a uma divisão equilibrada das mesmas. Por outro lado, este diferencial poderá entender-se melhor se repararmos que existem significativamente mais homens que mulheres $(43,1 \%$ vs. $17,8 \%)$ a referir que "colaboram em algumas tarefas" $(\chi 2=46,83, \mathrm{gl}=$ $2,559, p<0,001)$, sendo socializados para tal pela própria mulher, tal como refere um dos entrevistados:

Nas tarefas domésticas dividíamos, senti alguma dificuldade porque em solteiro, na casa da minha mãe não fazia, mas percebi que na vida a dois faz parte também isso. A divisão das tarefas domésticas é importante. Aprendi a fazer algumas coisas na cozinha, a lidar com o aspirador e a limpeza do pó foi feita em comum, e foi ela que me ensinou a fazer isso (entrevista n.. 13).

Por fim, a percentagem de inquiridos/as que afirmam não colaborar nesse tipo de tarefas configura-se diminuta, sendo ligeiramente superior por parte de homens (9,2\% vs 7,5\%), situação esta retratada por uma das entrevistadas: "Ele não fazia nada. Nunca estava 
presente. Nem um único chá, se eu estivesse doente, fazia. Nadinha. Não era pai presente, não era marido presente, não era nada" (A, 51 anos). Ou uma outra: "O meu ex-cônjuge nunca, nunca tratou das tarefas domésticas nem dos filhos. Compras, acompanhou-me sempre às compras, mas a responsabilidade é minha" (entrevista n.․ 16), sugerindo este último testemunho, por hábito incorporado, haver mulheres que assumem e não partilham as responsabilidades e tarefas com os homens. ${ }^{10}$ Introduzindo a variável profissão, verificamos também algumas diferenças relevantes, o que nos é dado pela figura 3.

Desde logo importa referir que são as mulheres, em quase todos os grupos profissionais, quem mais afirmam que "todas as tarefas são divididas", verificando-se as percentagens mais baixas no grupo das 'pequenas empresárias' $(66,7 \%)$ e as mais elevadas no das 'operadoras de instalações e máquinas de montagem' (100\%), grupos nos quais as mulheres se encontram subrepresentadas. As restantes percentagens variam, no caso destas, entre os $72,2 \%$ no grupo das 'operárias, artífices e trabalhadoras similares' e os 92,9\% no das 'técnicas e profissionais de nível intermédio'.

Figura 3. Grau de participação na divisão do trabalho doméstico por profi ssão e por sexo (\%)

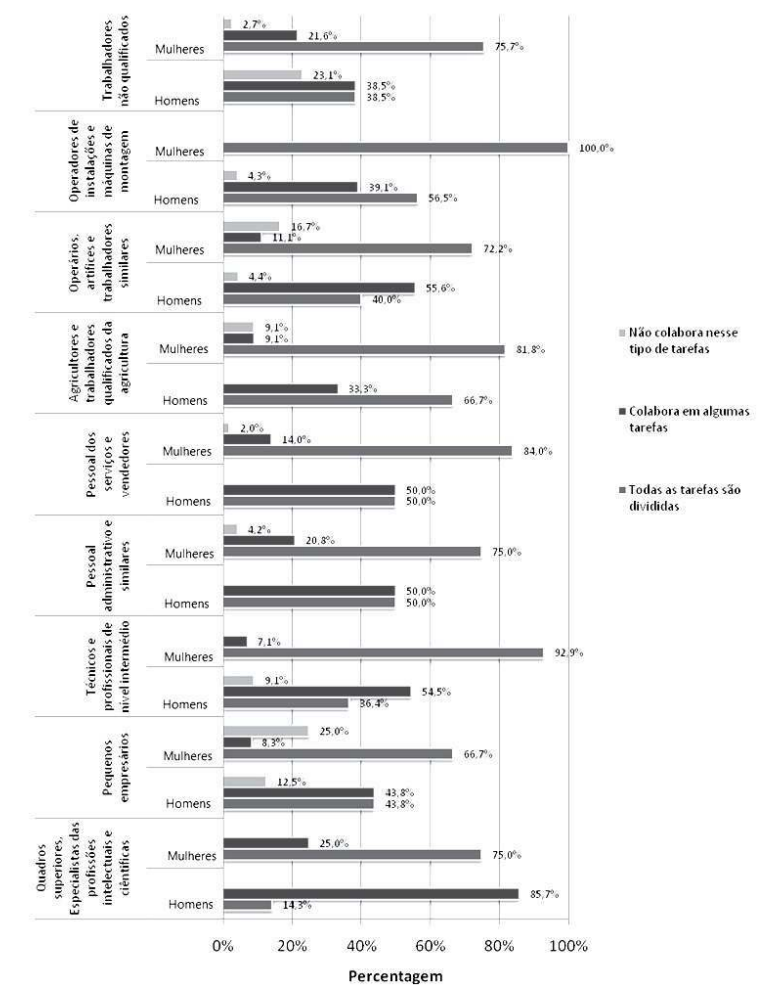

FONTE: IDG, 2011; N=465

Relativamente aos homens, à excepção do grupo dos 'agricultores e trabalhadores qualificados da agricultura' e dos 'operadores de instalações e máquinas de montagem' que afirmam com particular incidência que 'todas as tarefas são divididas' (respectivamente, 65,7\% e 56,5\%) - nos restantes as percentagens mais elevadas (ou em igual proporção) situam-se na afirmação de que 'colaboram em algumas tarefas', sendo de realçar aqui o grupo dos 'quadros superiores e especialistas das profissões intelectuais e científicas ( $85,7 \%$ vs $25 \%$ no caso das mulheres), conclusão esta convergente com a obtida por Sayer (2010) e Cooke (2004, 2010), na medida em que, para além da interiorização da norma igualitária, tem condições de contratualizar serviços domésticos. Mas vejamos 
agora a influência da idade neste contexto, passando a analisar as formas de divisão do trabalho doméstico e cruzá-las com os escalões etários, por sexo:

Figura 4. Grau de participação na divisão do trabalho doméstico por escalões etários e por sexo (\%)

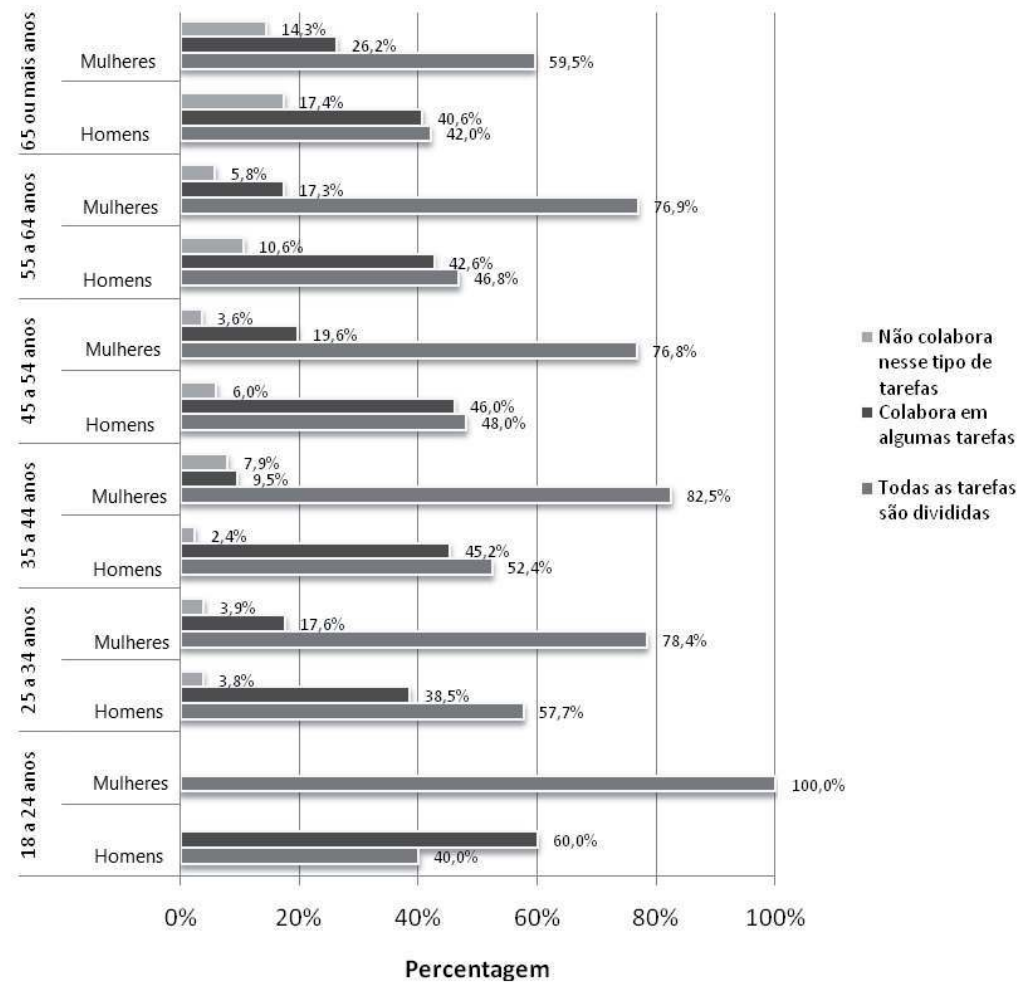

FONTE: IDG, 2011; N=802 (383 HOMENS; 419 MULHERES)

Tanto no caso dos homens como das mulheres existe uma tendencial correlação, inversamente proporcional, entre idade e grau de participação nas tarefas domésticas, ou seja, à medida em que se desce no escalão etário, aumenta o grau de divisão das tarefas domésticas, graças a mudanças geracionais nas expectativas de equidade de género no tratamento, disponibilidade de tempo e posse de recursos cognitivos (Sayer 2010: $20 \mathrm{ss}$ ). Porém, em termos percentuais, tal situação é bem mais evidente no caso das mulheres (verificando-se apenas valores muito aproximados nos escalões dos 45 e 54 anos e 55 e 64). No caso dos homens é notória uma distribuição mais irregular e, no que concerne à total partilha de tarefas, com percentagens que variam entre os $40 \%$ (no escalão dos 18 aos 24 anos) e os 57,5\% (no escalão dos 25 aos 34 anos). À excepção dos/as inquiridos/as mais jovens, a não colaboração neste tipo de tarefas surge em todos os grupos etários e é particularmente visível, quer nos homens quer nas mulheres, no grupo dos 65 anos e mais $(17,4 \%$ e $14,3 \%)$.

Uma das formas de medir o grau de ocupação e envolvimento nas tarefas domésticas e de cuidado aos filhos e outros dependentes consiste em saber qual o tempo despendido em diversas actividades, o que nos é dado pela fi gura 5: 
Figura 5. Média de horas semanais despendidas em actividade - o próprio, por sexo (\%)

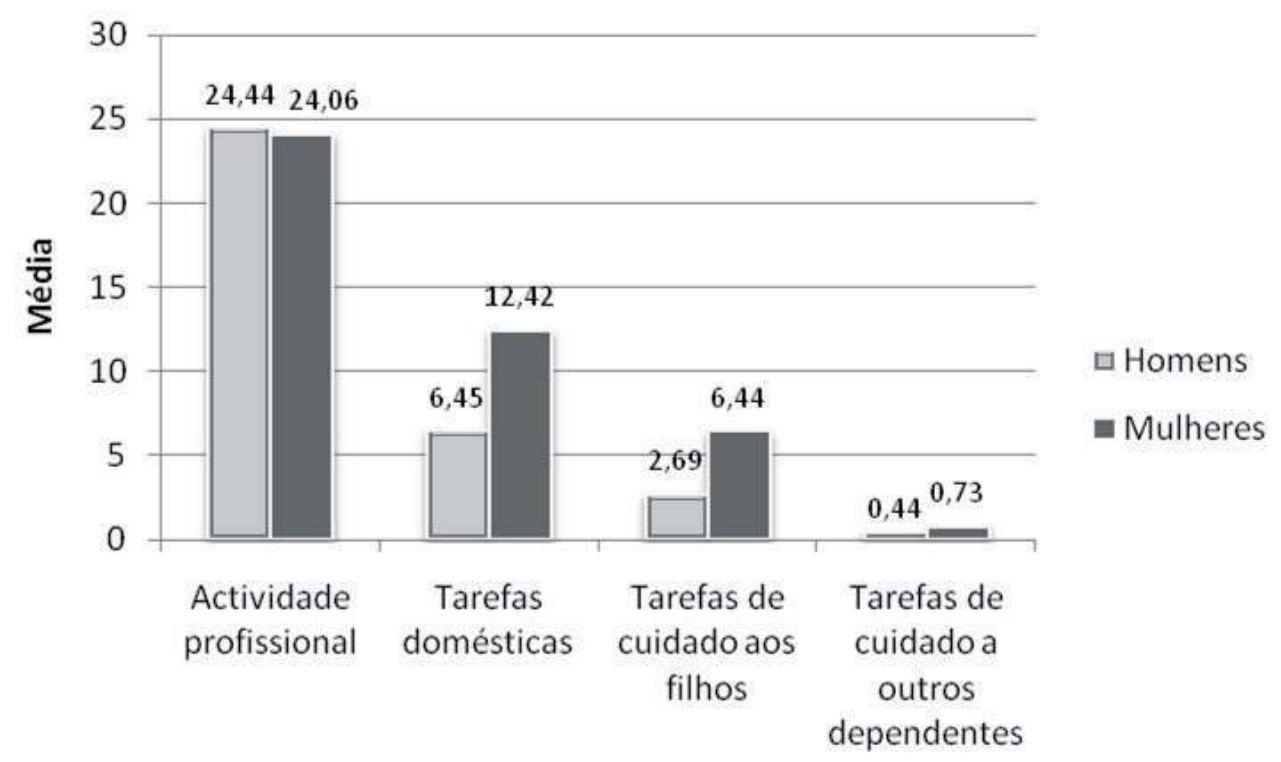

Fonte: IDG, 2011; N=802 (383 Homens; 419 Mulheres) ${ }^{11}$ mulheres inquiridos/as a distribuição de tempo do (ex)cônjuge pela actividade profissional, mais presente entre os homens, em contraponto com tarefas domésticas ${ }^{13}$, mais presente entre as mulheres. Confirma-se que a média de horas semanais despendidas na actividade profissional é, em média, de 24,22 horas com o desvio-padrão elevado de 21,60.

31 As horas semanais despendidas com tarefas de índole profissional apresentam valores que se podem configurar num primeiro momento como algo inesperado e tendencialmente baixo. Contudo, importa notar que tal decorre, em larga medida, da percentagem de inquiridos/as a trabalhar a tempo parcial, sendo que apenas 51,6\% dos inquiridos exerce profissão a tempo inteiro. Se considerarmos apenas estas pessoas, a média de horas semanais dispendidas na actividade profissional é de 38,34.

Outros aspectos parecem condicionar o número de horas dedicadas aos diversos tipos de tarefas. Releva aqui a importância da existência ou não de filhos na distribuição das mesmas. Efectivamente, é notória uma tendência para os/as inquiridos/as sem filhos dedicarem mais horas à actividade profissional do que os que têm filhos (respectivamente 30,4 horas vs 22,7 horas no caso dos homens e, no caso das mulheres, numa média de 30 horas vs 20,8 horas).

Também as horas despendidas com a profi ssão tendem a influenciar o tempo despendido noutras actividades, como se pode ver de seguida no quadro 1 : 
Quadro 1. Média de horas semanais despendidas pelo próprio por situação profissional e por sexo

\begin{tabular}{|c|c|c|c|c|c|c|c|c|}
\hline \multirow{2}{*}{$\begin{array}{l}\text { Situação face à } \\
\text { Profissão/Trabalho } \\
\\
\text { Situação } \\
\text { profissional }\end{array}$} & \multicolumn{2}{|c|}{$\begin{array}{l}\text { Actividade } \\
\text { profissional (o } \\
\text { próprio) }\end{array}$} & \multicolumn{2}{|c|}{$\begin{array}{c}\text { Tarefas } \\
\text { domésticas (o } \\
\text { próprio) }\end{array}$} & \multicolumn{2}{|c|}{$\begin{array}{c}\text { Tarefas de } \\
\text { cuidado aos } \\
\text { filhos (o próprio) }\end{array}$} & \multicolumn{2}{|c|}{$\begin{array}{c}\text { Tarefas de } \\
\text { cuidado } \\
\text { a outros } \\
\text { dependentes (o } \\
\text { próprio) }\end{array}$} \\
\hline & $\mathrm{H}$ & M & $\mathrm{H}$ & M & $\mathrm{H}$ & M & $\mathrm{H}$ & M \\
\hline $\begin{array}{l}\text { Exerce profissão a } \\
\text { tempo inteiro }\end{array}$ & 38,71 & 38,05 & 5,23 & 11,95 & 3,50 & 6,13 &, 12 &, 42 \\
\hline $\begin{array}{l}\text { Exerce profissão a } \\
\text { tempo parcial }\end{array}$ & 21,67 & 23,84 & 6,83 & 11,40 & 1,50 & 8,90 &, 00 &, 17 \\
\hline Desempregado(a) & 6,92 & 7,35 & 9,07 & 13,62 & 3,43 & 7,19 & 00 & 1,43 \\
\hline $\begin{array}{l}\text { Desempregado(a) } \\
\text { à procura de novo } \\
\text { emprego }\end{array}$ & 9,40 &, 29 & 8,92 & 17,87 & 4,67 & 15,27 &, 00 &, 13 \\
\hline Reformado(a) & 5,49 & 10,04 & 7,81 & 11,67 & 1,08 & 4,17 & 1,22 &, 85 \\
\hline Doméstica &, 00 &, 00 & 3,33 & 14,74 & ,00 & 6,67 &, 00 & 2,65 \\
\hline
\end{tabular}

\section{FONTE: IDG, 2011;N=465}

Verifica-se que, independentemente da situação profissional, no que concerne ao tempo despendido na profissão, são as mulheres quem mais tempo dedica a tarefas domésticas, ao cuidado dos filhos e também ao cuidado a outros dependentes, sobressaindo o grupo das 'desempregadas à procura de novo emprego' e 'domésticas' (em média, respectivamente, 17,87 e 14,74 horas semanais). No caso dos homens, seguindo a tendência acima indicada, é no grupo dos 'desempregados' e 'desempregados à procura de novo emprego' que se verificam médias mais elevadas de horas dedicadas a tarefas domésticas (respectivamente, 9,07 e 8,02) e, em menor escala, ao cuidado dos filhos $(3,42 \mathrm{e}$ $4,67)$, por comparação com os trabalhadores a tempo inteiro e parcial.

São os/as inquiridos/as que trabalham a tempo inteiro os/as que menos tempo despendem em tarefas domésticas e de cuidado, ainda que as diferenças relativamente aos/às que trabalham a tempo parcial não sejam particularmente relevantes no que toca a tarefas domésticas - as trabalhadoras a tempo inteiro despendem, em média, 11,95 horas e as trabalhadoras a tempo parcial 11,40; já os trabalhadores a tempo inteiro despendem 5,23 horas e os trabalhadores a tempo parcial 6,83 horas. Porém, a assimetria na distribuição de tarefas práticas torna-se evidente quando analisamos o volume e o grau de execução de tarefas domésticas específicas por sexo no seio do casal (cf. figura 6). 
Figura 6. Execução de tarefas entre membros do casal ${ }^{14}(\%)$

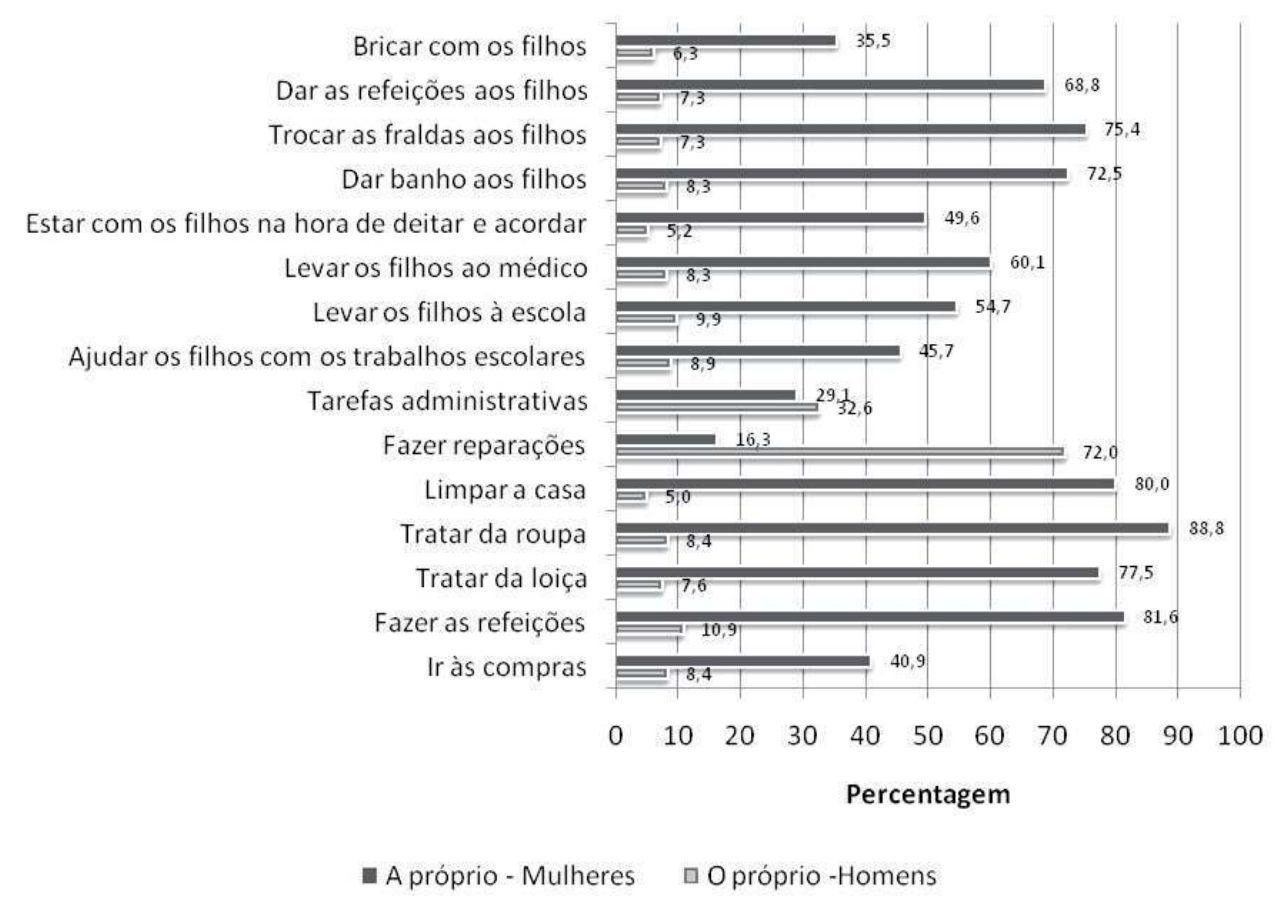

FONTE: IDG, 2011; N=559

0 sexo e a respectiva pertença de género afecta de forma significativa todas as tarefas do casal, nomeadamente em termos de auto-percepção. Existem quase sempre mais mulheres do que homens a referir serem elas e não o (ex)cônjuge ou companheiro quem desenvolve as tarefas, quer se trate de tarefas domésticas, quer de cuidados aos filhos e dependentes ${ }^{15}$. Se tal realidade pode ser, em alguns casos, aceite pelas próprias mulheres, não fosse a interiorização de tais normatividades, por parte das mesmas, noutros tende a ser questionada, como demonstra a seguinte passagem de entrevista:

$\mathrm{O}$ meu marido tinha comportamento à moda antiga. Achava ele que se mudasse a fralda às crianças, fizesse uma cama ou lavasse a louça perdia a masculinidade. Achava ele que o contributo económico era suficiente, que por sinal era mais pequeno que o meu. Chamem-lhe o que quiserem mas o que eu acho é que certos homens não passam de uns oportunistas. Querem as mulheres para satisfazer as suas necessidades sexuais, e para ter uma criada em casa. Depois...Quem gemer que diga de quê. (entrevista n. .014 )

O teor das tarefas desenvolvidas denuncia a existência de situações diferenciadas consoante o sexo. Em termos gerais, pode afirmar-se que é nas tarefas relativas às lides domésticas, mais rotineiras e menos valorizadas ('tratar da roupa', 'limpar a casa', 'fazer as refeições' e 'lavar a loiça'), que mais se evidenciam discrepâncias, com respostas sempre acima dos $80 \%$ por parte das mulheres e abaixo dos $11 \%$ por parte dos homens. A única tarefa no contexto doméstico, em que a percentagem de homens que afirma realizála é superior, corresponde às reparações domésticas $(72,0 \%$ vs. $16,3 \%)$. Relativamente às tarefas que remetem para um maior contacto com o exterior a situação configura-se menos assimétrica, sendo que no caso das 'tarefas administrativas' ou de contacto com serviços são os homens quem percentualmente mais afirma realizá-las, embora por pouca margem $(32,6 \% \text { vs. } 29,1 \%)^{16}$. O mesmo não acontece com as idas às compras, uma vez que também aqui é superior a percentagem de mulheres que afirma fazê-lo (40,9\% vs. 8,4\%). 
38 No que remete para as tarefas relacionadas com os cuidados com os filhos/as, as disparidades entre sexos tendem a ser ligeiramente inferiores às relativas às tarefas domésticas, ainda que igualmente elevadas. De qualquer forma é de relevar que elas se assumem particularmente expressivas ao nível das actividades de cuidado, nomeadamente para com crianças de tenra idade ('trocar as fraldas', 'dar banho', 'dar refeições'), situando-se todavia a percentagem de mulheres sempre acima dos $68 \%$ e a de homens abaixo dos $10 \%$. Uma das entrevistadas ilustra esta situação: "O meu ex-cônjuge nunca trocou uma fralda a um filho, nunca lhe deu um biberão, nunca ajudou a estudar nos trabalhos de casa, não fazia uma cama, não sabia cozinhar, não sabia nada dessas coisas." (entrevista 16).

39 Ainda que com elevado diferencial, onde é visível alguma colaboração por parte do homem é na tarefa de 'ajuda aos filhos com os trabalhos escolares' ( $45,7 \%$ pelas mães vs. $8,9 \%$ pelos pais-homens) e, particularmente ao nível da dimensão mais lúdica do cuidado: "brincar com os filhos", o que é levado a cabo por 35,5\% das mães vs $6,3 \%$ dos paishomens. Uma discrepância ainda acentuada é também visível ao nível das tarefas com os filhos em contexto exterior, como levar os filhos ao médico $(60,1 \%$ pelas mães e $8,3 \%$ pelos pais-homens) ou levar os filhos à escola (54,7\% pelas mães e $9 \%$ pelos pais-homens).

Por fim, considerando respostas "o próprio e o cônjuge", embora mais assinaladas por homens, há tarefas mais partilhadas por ambos como, por exemplo, a tarefa 'ir às compras', embora mais assinalada por homens (respectivamente 66,1\% vs. 51,6\%), 'ajudar os filhos com trabalhos escolares ou levar os filhos ao médico' (51,6\% vs. 37\% no primeiro caso e $53,1 \%$ para $35,9 \%$ no segundo). Comparativamente ao passado mais recuado, são sentidas, inclusive por algumas mulheres, certo progresso nas práticas igualitárias, tal como o testemunha uma entrevistada: "Sabe, eu tive sorte com o pai das minhas filhas, porque ele sempre colaborou nas tarefas domésticas" (entrevista n.․ 8) ou uma outra:

Não eram divididas irmãmente... mas ajudava muito, na realização de tarefas como, por exemplo, levar e ir buscar os meninos ao colégio, dar banho as crianças, dava apoio nas tarefas escolares, na realização das refeições etc. (entrevista n. ${ }^{\circ}$ )

41 Atendendo ao grupo profissional e escalão etário de pertença dos/as inquiridos/as não se verificam diferenças significativas, seguindo-se as tendências avançadas relativamente às outras questões analisadas e que devem ser analisadas à luz das desiguais frequências entre grupos.

\section{Os cuidados com os filhos: entre a função expressiva e as expressões assimétricas}

Outro dos pontos-chave na eventual assimetria de género consiste na divisão sexual do trabalho no que concerne o cuidado dos filhos. Verificamos assim que, no quadro da afectividade que parece assumir-se como vector central ao nível da parentalidade, outros aspectos convergem na importância assumida pelos filhos na família, que se prendem quer com com o amor, a alegria e a consequente valorização da conjugalidade, quer com razões de índole mais instrumental, como seja a continuidade patrimonial, aspectos que assumem ligeiras diferenças consoante o sexo ${ }^{17}$. Se é inequívoca a centralidade dos filhos assumida, importa agora analisar uma outra dimensão, que se prende com a forma ideal quanto ao cuidado com os mesmos preconizada pelos/as inquiridos/as. Independentemente do sexo, as respostas, na sua maioria, revelam o entendimento de 
que o casal deveria dividir, de modo equilibrado, todas as tarefas de cuidado com os filhos $(69,2 \%)$. No entanto, é ainda relevante a percentagem dos/as que entendem que o marido deve ajudar $(28,9 \%)$, depreendendo-se deste entendimento que o grosso dessas tarefas deve ser realizado pela mulher. Mas, considerando as respostas a esta questão por sexo, obtemos os resultados que se podem ver na figura 7 :

Figura 7. Forma ideal de divisão de cuidados dos filhos, por sexo (\%)

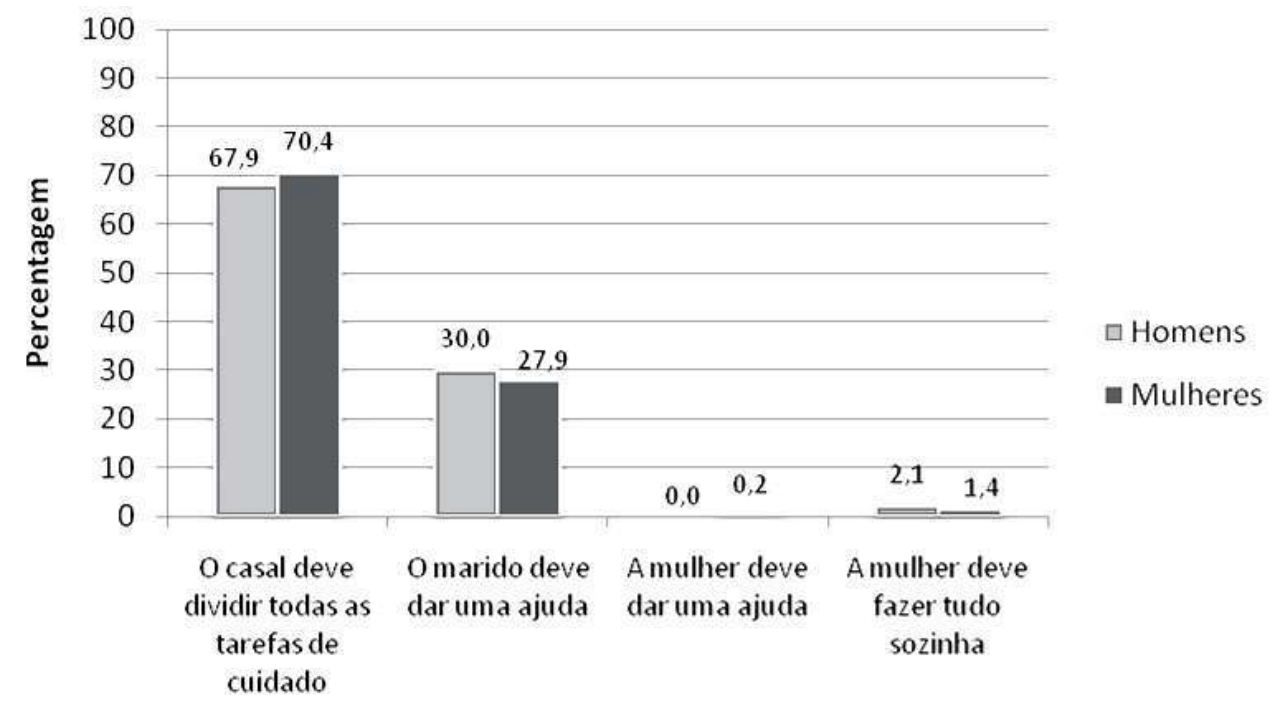

FONTE: IDG, 2011; N=497 diminutas, sendo ligeiramente superior a percentagem de mulheres que afirma que "o casal deve dividir todas as tarefas de cuidados" (70,4\% para $67,9 \%)$. Já relativamente à opção "o marido deve dar uma ajuda", é entre os homens que a percentagem se assume ligeiramente mais elevada, sem deixar de ser evidenciada pelas mulheres (30\% para $27,9 \%$ ). As respostas expressas nas figuras 2 e 7 são denotativas de que as mentalidades e percepções não só dos homens como das mulheres a este respeito ainda se encontram incrustadas no padrão tradicional, ${ }^{18}$ também e sobretudo presente nas respostas residuais de que "a mulher deve fazer tudo sozinha" (2,1\% homens vs $1,4 \%$ mulheres): "O que acontece é que somos levados por aquilo que é a tradição e que a sociedade nos incute. Os homens são mais para fora de casa e as mulheres mais para dentro, embora hoje esteja bem diferente (homem, 46 anos). Ou, na opinião de uma das entrevistadas: "Nunca houve distribuição de tarefas...Talvez culpa minha...porque eu achava que era uma supermulher e conseguia fazer tudo sozinha" (mulher, 48 anos).

A análise destas concepções atendendo ao grupo profissional de pertença é também demonstrativa de algumas diferenças. Em todas as profissões, sejam homens ou mulheres, a maioria dos/as inquiridos/as considera que 'o casal deve dividir todas as tarefas de cuidado' (com percentagens sempre iguais ou superiores a 50\%). As percentagens mais elevadas, quanto às mulheres, verificam-se ao nível das profissões que exigem qualificações intermédias, no grupo dos 'técnicos e profissionais de nível intermédio' (86,4\%), do 'pessoal dos serviços e vendedores' $(82,4 \%)$ e do 'pessoal administrativo e similares (80,6\%). Relativamente aos homens (exceptuando os militares em que a percentagem é de $100 \%$ mas o número de inquiridos muito reduzido ${ }^{19}$ ), os únicos grupos nos quais as percentagens superam os $80 \%$, sendo inclusive ligeiramente superior à das 
mulheres, remetem para os extremos em termos de habilitações e qualificações, relevando os quadros superiores e especialistas das profissões técnicas e científicas' $(82,6 \%$ vs $77,8 \%)$ e os 'operadores de instalações e máquinas de montagem' ( $80 \%$ vs $50 \%)$.

Quanto à resposta 'o marido deve dar uma ajuda', se no caso das mulheres ela apresenta percentagens mais elevadas nas profissões intermédias ou menos qualificadas (operadoras de instalações e máquinas de montagem com 50\%, agricultoras com 45,5\%, trabalhadoras não qualificadas com $36 \%$, pequenas empresárias com 30,8\%), relativamente aos homens tal resposta verifica-se no grupo dos agricultores (54,5\%), operadores de instalações e máquinas de montagem com $50 \%$, pequenos empresários $(47,4 \%)$ e pessoal dos serviços e vendedores $(40 \%)$. No extremo, em que se assume que 'a mulher deve fazer tudo sozinha', denotam-se percentagens muito residuais, por parte quer de homens, quer sobretudo de mulheres (entre 7,7\% e 1,75\%).

Tendo presente as concepções e representações sobre a partilha dos cuidados com os filhos, importa contrastá-las com as práticas reais de quem, ainda na pendência do casamento ou união de facto, se encarrega de ficar com os filhos. Questionados a este respeito, os/as inquiridos/as afirmaram maioritariamente que os filhos ficavam a cargo ou do próprio ou do cônjuge desde o primeiro ao quarto filho respectivamente $(38 \%, 25 \%$, $10 \%, 4 \%)$, mas também é relevante, quer na casa com outro familiar $(15 \%, 7 \%, 3 \%, 1 \%)$, quer na creche ou no infantário $(15 \%, 8 \%, 2 \%, 1 \%)$, havendo muito poucos pais com mais de 4 filhos, aliás com percentagens residuais. Porém, mais relevante é, diferenciando por sexo, atender a quem fica a cuidar dos filhos, o que nos é dado pela figura 8:

Figura 8. Distribuição dos cuidados quotidianos dos filhos pelo pai ou mãe (\%)

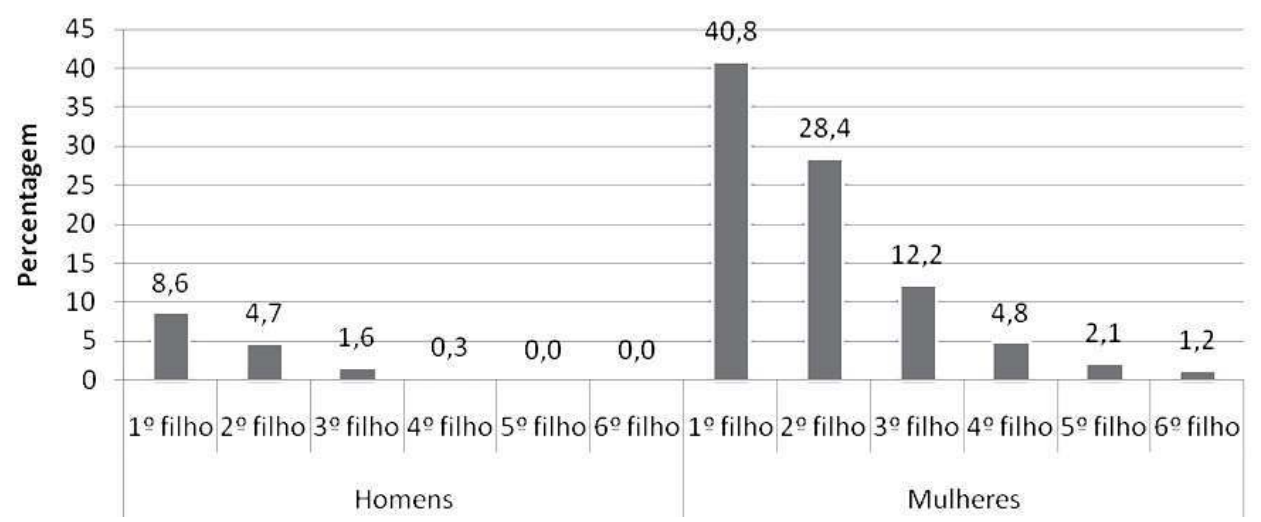

Fonte: IDG, $2011 ; 1 .{ }^{\circ}$ filho: $\mathrm{N}=497 ; 2^{\circ}{ }^{\circ}$ filho: $\mathrm{N}=299 ; 3 .{ }^{\circ}$ filho: $\mathrm{N}=109 ; 4 .^{\circ}$ filho: $\mathrm{N}=36 ; 5 .^{\circ}$ filho: $\mathrm{N}=13 ; 6 .^{\circ}$ filho: $N=7$

Desta figura se infere que o facto de os filhos ficarem em casa com um dos pais não é independente do sexo. Com efeito, há significativamente mais mulheres do que homens a mencionar que os filhos ficavam em casa consigo ${ }^{20}$. A constatação desta realidade é reforçada quando questionados se os filhos ficavam em casa com o cônjuge. Efectivamente, o facto de os participantes mencionarem que os filhos ficavam em casa com o cônjuge também não é independente do sexo na medida em que há significativamente mais homens do que mulheres a fazerem esta afirmação ${ }^{21}$. Tais afirmações dos homens confirmam que são as suas mulheres a ficarem, na maior parte dos casos, com os filhos. 


\section{Conclusão}

48 de género, analisa representações e práticas de homens e mulheres sobre a divisão de tarefas domésticas, traduzindo amiúde discursos e aspirações de repartição (mais) equitativa das tarefas domésticas e dos cuidados com os filhos. Estas concepções de "equidade" ainda se revelam, todavia, em parte insatisfatórias, não só por parte de homens que adoptam práticas discrepantes com as opiniões emitidas ou se sentem avessos ou distantes quanto à repartição equitativa de actividades domésticas, como por parte de mulheres que tendem a assumir tais tarefas como suas, aceitando ou relativizando a ausência de participação ou irregularidade de colaboração dos homens nas tarefas domésticas. Por outro lado, o facto de existir alguma colaboração por parte dos homens é potenciada e, subsequentemente, por estes sobrevalorizada. Mais, embora as respostas e discursos apontem para um ideal de repartição paritária de tarefas, as práticas desmentem parcialmente esse ideal normativo, verificando-se, na maior parte dos casos, uma menor participação por parte dos homens em tarefas concretas e em numero de horas despendidas.

Esta discrepância prolonga-se nos cuidados e tempos despendidos com os filhos com sobrecarga para a mulher. Contrariamente à perspectiva legitimadora da visão parsoniana, não se trata de uma função expressiva complementar da função instrumental exercida pelo homem mas antes de uma expressão assimétrica de papéis em prejuízo da mulher. Às representações de complementaridade opõem-se práticas assimétricas de género no espaço doméstico.

Do confronto das várias posições sobre as representações sociais e do contributo sintético de Bourdieu em torno da lógica da prática $(1980,1989)$ acrescido de algumas perspectivas psicológicas, podemos inferir que as convergências e as discrepâncias entre representações e práticas quotidianas entre homens e mulheres na esfera doméstica derivam dos lugares ocupados por cada no contexto social e familiar e do grau de disposição sobre determinados recursos, não sendo imune ao conjunto de recursos possuídos por cada um. E, mais especificamente, em relação à divisão de tarefas domésticas e cuidados com os filhos no âmbito da relação conjugal, é a condição de mulher e de mãe que acaba por implicar uma sobrecarga de trabalho.

51 Se as representações sociais não devem ser menosprezadas na medida em que integram e influenciam, de certo modo, as práticas dos actores sociais na vida conjugal, a prática constitui o principal critério aferidor da distribuição (as)simétrica do trabalho doméstico. Se, por um lado, é reconhecida a discrepância entre representações e práticas quer entre as mulheres, quer mesmo entre os homens, também é verdade que os dados do inquérito e das entrevistas evidenciam que, nas experiências e práticas no quotidiano de homens e mulheres e respectivos contextos familiares, há elementos não só de conservação mas também de mudança e progresso, nomeadamente alguma diminuição nas assimetrias de género no espaço doméstico. Por outro lado, se as representações e opiniões convergentes expressas por homens e mulheres traduzem ora atitudes e práticas reveladoras de afectos e emoções ora interesses comuns induzidos ou não ideologicamente, as diferenciadas representações e sobretudo práticas por sexo são denotativas de certos interesses opostos específicos de género e, como tal, exigem mudança de papéis, representações e 
mentalidades, assim como a colaboração de empresas e sindicatos e, sobretudo, adequadas políticas públicas.

\section{BIBLIOGRAPHY}

ALLEN, Sarah e HAWKINGS, Alan (1999), “Maternal gatekeeping: Mother's beliefs and behaviors that inhibit greater father involvement in family work" in Journal of Marriage and the Family, 61: 199-212.

ALMEIDA, Ana Nunes de (1993), A Fábrica e a Família: Famílias Operárias do Barreiro, Barreiro: Câmara Municipal do Barreiro.

ALMEIDA, João Ferreira (1986), Classes sociais nos campos. Camponeses parciais numa região do Noroeste, Lisboa: Instituto de Ciências Sociais, Universidade de Lisboa.

AMÂNCIO, Lígia (1993), “Género - representações e identidades” in Sociologia Problemas e Práticas, 14:127-140.

AMÂNCIO, Lígia (1994), Masculino e Feminino. A construção social da diferença, Porto:Afrontamento. AMARO, Fausto (2009), "Políticas Públicas de Família - Algumas Tendências" in O sentido de mudança: políticas públicas em Portugal, 2005-2009, Lisboa: Fundação Res Publica, pp. 71-82.

BECKER, Penny E. e MOEN, Phylis (1999), “Scalling back: Dual-earner couples work-family strategies" in Journal of Marriage and Family, 61: 995-1007.

BIELBY, William e BIELBY, Denise (1989), "Family ties: Balancing commitments to work and family in dual earner households" in American Sociological Review, 54:776-789.

BLAIR, Sampson L. e LICHTER, Daniel T. (1991),"Measuring the division of household labor: gender segregation of housework among American couples" in Journal of Family Issues, 12:759-790. BOURDIEU, Pierre (1980), Le sens pratique, Paris: Minuit.

BOURDIEU, Pierre (1989), o poder simbólico, Lisboa: Difel.

BOURDIEU, Pierre (1998), La domination masculine, Paris: Seuil.

BUDIG, Michele e ENGLAND, Paula (2001), « The wage penalty for motherhood » in American Sociological Review, 66: 204-224.

CABECINHAS, Rosa (2004), "Representações sociais, relações intergrupais e cognição social" in Paidéia, Vol. 14, 28, 125-137.

CHARLES, Maria e CECH, Erin (2010), « Beliefs about Matenal Employment » in J.Treas e S. Drobnic (eds), Dividing Domestic. Men, Women and Household Work, Standford, California: Standford University Press, pp. 147-174.

COOKE, Lynn Prince (2004), « The gendered division of labour and family outcomes in Germany» in Journal of Marriage and Family, 66 :1246-1259. 
COOKE, Lynn Prince (2010), « The Politics of Household» in J.Treas e S. Drobnic (eds), Dividing Domestic. Men, Women and Household Work, Standford, California: Standford University Press, pp. 59-78.

COMPTON, Rosemary, BROCKMANN, Michaela e Lyonette, Clare (2005), «Attitudes, women's employment and the domestic division of labour» in Work, Employment and Society, 19:213-233.

CUNHA, Vanessa (2005), “As funções sociais dos fi lhos” in K. Wall (org.), Familias em Portugal Percursos, Interacções e Redes Sociais, Lisboa: Imprensa das Ciências Sociais.

DEX, Shirley (2010), « Can the State Policies Produce Equality in Housework » in J.Treas e S. Drobnic (eds), Dividing Domestic. Men, Women and Household Work, Standford, California: Standford University Press, pp. 79-104.

DROBBNIC, Sonja (2010), « Concluding Thoughts on the Societal Context of Housework », in J.Treas e S. Drobnic (eds), Dividing Domestic. Men, Women and Household Work, Standford, California: Standford University Press, pp. 241-251.

DUBISCH, Jill (1986), «Introduction» in J. Dubisch (org), Gender and Power in Rural Greece, Princeton, Nova Jersey : Princeton University Press.

DURKHEIM, Emile [1974(1895)], Las reglas del método sociológico, Madrid:Morata.

ENGELS, Friedrich (1980), A origem da familia, da propriedade e do Estado, Lisboa: Editorial Presença. ESPING-ANDERSEN, Gosta (2009), Três Lições sobre o Estado-Providência, Lisboa: Campo da Comunicação.

GEIST, Claudia (2005), «The welfare state and the home: Regime differences in the domestic division of labour» in European Sociological Review, 69:751-767.

GEIST, Claudia (2010), «Men and Women's Reports about Housework» in J. Treas e S. Drobnic (eds), Dividing Domestic. Men, Women and Household Work, Standford, California: Standford University Press, pp. 217-240.

GOFFMAN, Erving (1989), A representação do eu na vida quotidiana, Petrópolis:Vozes.

GRAMSCI, Antonio (1974), Obras escolhidas, , I e II, Lisboa: Estampa.

GUERREIRO, Maria das Dores (2005), “A divisão familiar do trabalho” in K. Wall (org.), Famílias em Portugal - Percursos, Interacções e Redes Sociais, Lisboa: Imprensa das Ciências Sociais.

GUPTA, Jansij (1999), “The effects of marital status transitions on men's housework performance" in Journal of Marriage Studies and the Family, 61:700-711.

LEANDRO, Maria Engrácia (2001), Sociologia da Familia nas Sociedades Contemporâneas, Lisboa: Universidade Aberta.

LEFEBVRE, Henry (1977), Critique de la vie quotidienne, Paris:L'Arche.

LOBO, Cristina (2009), Recomposições familiares: dinâmicas de um processo de transição, Lisboa: Fundação Calouste Gulbenkian e Fundação para a Ciência e Tecnologia.

LUKÁCS, George (1967), Existencialismo ou Marxismo?, São Paulo:Senzala.

MACHADO, Helena (2007), Moralizar para identificar. Cenários da investigação judicial de paternidade, Porto: Afrontamento.

MARQUES, Ana P., Silva, M. Carlos e Veiga, Carlos (2007), Assimetrias de Género e Classe. 0 caso das empresas de Barcelos, Barcelos: Kerigma.

MARX [1971 (1859), Contribuição para a crítica da economia política, Lisboa: Estampa 
MARX, Karl e ENGELS, Friedrich [1976(1846)], A ideologia alemã, Lisboa: Presença.

MEAD, Herbert (1934), Mind, Self and Society: from the Standpoint of a Social Behaviorist, Chicago: University of Chicago Press.

MOSCIVICI, Serge (1989), «Des representations collectives aux Representations Sociales» in D. Jodelet (org), Les representations sociales : 62-86, Paris : Presses Universitaires de France.

NOGUEIRA, Conceição (1997), Um novo olhar sobre as relações sociais de género. Perspectiva feminista crítica na Psicologia Social. Braga: Universidade do Minho.

PARSONS, Talcott (1956), «Family Structure and the Socialization of the Child» in T. Parsons e R. F. Bales (orgs), Family, Socialization and Interaction Process:35-131, Londres: Routledge and Kegan Paul.

PFAU-EFFINGER, Birgit (2004), « Socio-historical paths of the male breadwinner model:An explanation of Cross-National differences » in British Journal of Sociology, 55 :377-399.

PFAU-EFFINGER, Birgit (2010), «Cultural and Institucional Contexts» in J. Treas e S. Drobnic (eds), Dividing Domestic. Men, Women and Household Work, Standford, California: Standford University Press, pp. 125-146.

PINTO, José Madureira (1985), Estruturas sociais e práticas simbólico-ideológicas nos campos, Porto:Afrontamento.

PORTUGAL, Sílvia (2004), "Retórica e acção governativa na área das políticas de família desde 2004" in Revista Crítica de Ciências Sociais, 56: 81-92.

ROHLER, Karl Alexander e HUININK, Johannes (2010), "Pair Relationships and Housework" in J. Treas e S. Drobnic (eds), Dividing Domestic. Men, Women and Household Work, Standford, California: Standford University Press, pp. 192-213.

SANTOS, Boaventura de Sousa (1990), “O Estado e o Direito na transição pós-moderna” in Revista Crítica de Ciências Sociais, 30:13-43.

SAYER, Liana (2010), “Trends in Housework” in J. Treas e S. Drobnic (Eds.), Dividing Domestic Men, Women and Household, Standford: Standford University Press, pp. 19-38.

SCHUTZ, Alfred (1993), La construción significativa del mundo social. Introducción a la Sociología compreensiva, Barcelons:Editorial Paidós.

SILVA, Manuel Carlos (1991), "Casa e casas em espaço rural minhoto: o poder doméstico" in Cadernos de Noroeste, vol 4, n 6-7:79-99.

SILVA, Manuel Carlos (1998), Resistir e adaptar-se. Constrangimentos e estratégias camponesas no Nororeste de Portugal, Porto: Afrontamento.

SILVA (2004), "Honra e vergonha: código cultural mediterrânico ou forma de controlo de mulheres?” in J. Portela e J.C.Caldas (orgs), Portugal-Chão:67-86, Oeiras:Celta Editora.

SIMMEL, Georg (1977), Sociologia. Estudios sobre las formas de socialización, 2 vols., Madrid: Revista de Occidente/Alianza Editorial.

SOBRAL, José Manuel (1999), Trajectos: passado e presente na vida de uma freguesia da Beira, Lisboa: Instituto de Ciências Sociais da Universidade de Lisboa.

TORRES, Anália (2001), Sociologia do Casamento. A Família e a Questão Feminina. Oeiras:Celta.

TREAS, Judith (2010), “Why Study Housework?” in J.Treas e S. Drobnic (eds), Dividing Domestic. Men, Women and Household Work, Standford, California: Standford University Press, pp. 3-18. 
TREAS, Judith e DE RUYTER, Esther (2008), “Earnings and expenditures on household services in married and cohabiting unions" in Journal of Marriage and Family, 70:796-805.

VALA, Jorge (1993), "Representações sociais e psicologia do conhecimento quotidiano" in J. Vala e M.B. Monteiro (orgs), Psicologia Social:475-502, Lisboa:Fundação Calouste Gulbenkian.

VAN DER LIPPE, Tanja, TIJDENS, Kea e DE RUYTER, Esther (2004), “Outsourcing of domestic tasks and timesaving effect" in Journal of Social Issues, 25: 216-240.

VAN DER LIPPE, Tanja (2010), “Women's employment and Housework” in J. Treas e S. Drobnic (eds), Dividing Domestic. Men, Women and Household Work, Standford, California: Standford University Press, pp. 41-58.

WALL, Karin (1998), Famílias no campo: passado e presente em duas freguesias do Baixo Minho, Lisboa: Dom Quixote.

WALL, Karin (2005), Famílias no Portugal Contemporâneo - Percursos, Interacções, Redes Sociais, Lisboa: Imprensa das Ciências Sociais

WALL, Karin, ABOIM, Sofi a e CUNHA, Vanessa (orgs.) (2010), A vida familiar no masculino: negociando velhas e novas masculinidades, Lisboa: Comissão para a Igualdade no Trabalho e no Emprego.

WALL, Karin e AMANCIO, Lígia (2007), Familia e Género em Portugal, Lisboa: Imprensa de Ciencias Sociais.

WEBER, Max, [1990 (1905)] A ética protestante e o espírito do capitalismo, Lisboa:Presença.

WEBER, Max [1978(1920)], Economy and Society, editado por G.Roth e C. Wittich, Berkeley e Londres: University of California Press.

\section{NOTES}

1. Este inquérito insere-se no quadro de um projecto aprovado e financiado pela FCT e finalizado em 2011 (PTDC/SDE/72257/2006). Nesta amostra por quotas foram tidas em conta as variáveis referidas, sendo de esclarecer que, quanto à variável activo-não activo, tem-se em vista a distinção entre pessoas activas no formal sistema de emprego e as não activas (estudantes, desempregados, reformados), mesmo quando estes possam ser activos nomeadamente no âmbito doméstico. Para além da participação no projecto por parte de Aleksandra Queiroz, agradecemos a recolha suplementar dalgumas entrevistas por Gorety Diogo e Judite Peixoto, finalistas do curso de Sociologia na Universidade do Minho.

2. O primeiro autor, retomando o tema a partir de um capítulo da tese de doutoramento e de um outro texto anterior (Silva 1998, 1991), apresentou no VII Congresso Português de Sociologia em 2012 um segundo texto sobre a questão mais sensível das relações entre membros do casal no que respeita o exercício do efectivo poder doméstico em vários aspectos da vida conjugal.

3. Para uma abordagem relevando as influências culturais e institucionais, cf. Pfau-Effinger (2010) ou, de modo mais específico, as ideias sobre maternidade, em caso de fraco ou nulo apoio estatal à família e cuidado dos filhos, podem induzir a mulher a cuidar deles em casa (Charles e Cech 2010).

4. Contrariamente à perspectiva durkheimiana, Moscovici (1989) admite, para além das representações dominantes, as dissidentes e emancipatórias. Em Portugal este tema tem sido também largamente trabalhado por vários psicólogos sociais, entre os quais Vala (1993), Cabecinhas (2004) e, relativamente às representações do masculino e do feminino, Amâncio (1993, 1994); Nogueira (1997). 
5. Embora possa sustentar-se uma determinada correlação entre grau de recursos e recompensas e medida de poder doméstico e distribuição de tarefas domésticas, tal não ocorre de modo mecânico e, muito menos, absoluto, pois, tal como refere Gupta (1999), homens com menor rendimento e menos horas de trabalho extradoméstico nem sempre dedicam maior tempo às tarefas domésticas por ser entendidas como "tarefas femininas" à luz da ideologia patriarcal dominante.

6. A fim de evitar uma leitura simplista e mecânica, é de referir, sendo o objecto e campo de estudo empírico e comparativo o tipo de relações familiares entre alemães ocidentais e orientais, que os autores concluem, num aparente paradoxo, que as famílias da Alemanha do Leste, apesar de se subsumirem no padrão de relações afectivas tradicionais, provavelmente por processos de socialização e pelo facto de as mulheres trabalharem em full time e sobretudo pelo lastro da política social do ex-regime estatista no Leste, apresentam um padrão mais igualitário do que na Alemanha ocidental.

7. Em Portugal, estas matérias têm sido abordadas por Almeida (1986:236 s), 149 s), Silva (1991, 1998), A. Almeida (1993), Wall (1998), Sobral (1999), Torres (2001), Leandro (2001), Portugal (2004), Guerreiro (2005), Marques et al (2006), Wall e Amâncio (2007), Machado (2007), Lobo (2009), Amaro (2009), Wall, Aboim e Cunha (2010). Porém, foi Karin Wall e colaboradores (2005) quem, de modo mais sistemático, com base em resultados de um inquérito a nível nacional, analisaram os padrões comportamentais na repartição das tarefas no âmbito doméstico, destacando como relevantes o factor cultural e políticoinstitucional.

8. Cf., a este propósito, as conclusões doutros estudos, nomeadamente de Bielby e Bielby (1989) Becker e Moen (1999), Budig e England (2001) e Wall et al (2005).

9. Constatável noutros estudos nacionais e internacionais: Wall et al (2005), Van der Lippe et al (2004), De Ruyter, Treas e Cohen, (2005), Treas e De Ruyter (2008). Mais presente, segundo a abordagem cultural de Pfau-Effinger (2004), em países de tradição de 'cultura servil' no sul de Europa que nos países nórdicos.

10. Semelhante conclusão foi igualmente verificada em estudo de Allen e Hawkins (1999).

11. Inquiridos/as activos/as $\mathrm{N}=465$ (226 Homens e 239 Mulheres); Inquiridos/as com fi lhos $\mathrm{N}=497$ (244 Homens e 253 Mulheres). A média global de horas em actividade profissional é baixa por englobar os trabalhos a tempo inteiro, parcial e os ditos inactivos.

12. $O$ que se vê pelos resultados do teste estatístico, respectivamente, $t(539,21)=-7,45, p<0,001)(t$ $(469,18)=-4,90, p<0,001)$. Sayer $(2010)$ após confrontar as perspectivas económica e de género sobre o tempo de trabalho doméstico, analisa com base numa amostra internacional ( Multinational Time Use Study-MTUS), o uso diversificado do tempo, focalizando o estudo sobre o tempo despendido no trabalho doméstico em vários países de 1965 a 2000. Embora com diferenças por países, a autora constata, em geral, uma diminuição de tempo de trabalho doméstico por parte da mulher, um relativo aumento do mesmo por parte do homem, mas mantendo-se a diferença por género (passando de 3,5:1 em 1970 para 1,5 a 2:1 em 2000). No que concerne a Portugal, esta relação de 1,6 nas respostas converge com os resultados de pesquisa realizada por Geist (2010) em relação aos relatos de mulheres e homens sobre o tempo de trabalho doméstico em 35 países com base nos dados da International Social Survey Programme (ISSP) em 2002 (no caso de Portugal o cálculo da autora é de 1,28).

13. Consubstanciando-se este dado nos seguintes resultados: $(t(424)=-4,09, p<0,001)(t(285,46)=$ $8,88, p<0,001)$

14. As possibilidades de resposta a estas questões são: "o próprio", “o cônjuge”, “o próprio e filhos", "o próprio e cônjuge", “o próprio, cônjuge e filhos" e "não fazíamos estas tarefas". Para simplificar a apresentação gráfica por género, apenas as percentagens para o próprio são apresentadas. $\mathrm{O}$ facto de serem limitadas as opções pode condicionar a análise. Em todo o caso é 
de assumir este tratamento como ilustrativo, mas não deixa de ser relevante na medida em que se trata dos principais protagonistas na casa.

15. Assumem-se como particularmente relevantes a este nível tarefas como tratar da roupa (88,8\% vs. $8,4 \%: \chi 2=404,21, \mathrm{gl}=6,559, \mathrm{p}<0,001)$; ir às compras $(40,9 \%$ vs. $8,4 \%: \chi 2=$ 99,48, gl= 6,559, p < 0,001); fazer refeições (81,6\% vs. 10,9\%: $\chi 2=311,55, \mathrm{gl}=6,559, \mathrm{p}<0,001)$; limpar a casa ( $80 \%$ vs. $5 \%: \chi 2=354,55, \mathrm{gl}=7,559, \mathrm{p}<0,001)$; tratar da loiça $(77,5 \%$ vs. 7,6\%: $\chi 2=320,20, \mathrm{gl}=7,558, \mathrm{p}<0,001)$; trocar as fraldas aos filhos $(75,4 \%$ vs. $7,3 \%: \chi 2=259,22, \mathrm{gl}=$ $6,468, \mathrm{p}<0,001$; dar banho aos filhos 72,5\% vs. 8,3\%: $\mathrm{x} 2=226,03, \mathrm{gl}=6,468, \mathrm{p}<0,001$ ); dar as refeições aos fi lhos (68,8\% vs. 7,3\%: $\chi 2=224,79, \mathrm{gl}=5,468, \mathrm{p}<0,001$; levar os filhos ao médico (60,1\% vs. 8,3\%: $\chi 2=174,93, \mathrm{gl}=5,468, \mathrm{p}<0,001)$; levar os filhos à escola (54,7\% vs. 9,9\%: $\chi 2=128,80, \mathrm{gl}=6,468, \mathrm{p}<0,001)$; estar com os filhos na hora de deitar e acordar (49,6\% vs. 5,2\%:x2=146,20, gl=6,468, p < 0,001); ajudar os filhos com os trabalhos escolares $(45,7 \%$ vs. $8,9 \%: \chi 2=108,72, \mathrm{gl}=6,468, \mathrm{p}<0,001)$; brincar com os filhos $(35,5 \%$ vs. $6,3 \%: \chi 2=$ $66,65, \mathrm{gl}=6,468, \mathrm{p}<0,001)$. Sobre a sobrecarga de tarefas rotineiras e fastidiantes, cf. Blair e Lichter (1991).

16. Respectivamente $\chi 2=209,63, g l=7,559, p<0,001$ e $\chi 2=17,34 g l=6,559, p<0,01)$. Em todos estes testes do Qui-quadrado verifica-se que algumas das células apresentam frequências esperadas inferiores a 5 . Nesta situação o teste não pode ser aplicado com rigor. Assim, procedeu-se à realização do teste do Qui-quadrado por simulação de Monte-Carlo que permitiu confirmar os resultados, com $p<0,001$ para todas as questões, com excepção da simulação para as tarefas administrativas, cujo nível de significância é de $p<0,01$. Por outro lado, a mesma análise, considerando apenas duas das categorias de resposta ("o próprio" e "o cônjuge), confirma que as diferenças observadas são de facto significativas.

17. Para $53,4 \%$ de homens e $52,5 \%$ de mulheres os filhos são 'fonte de alegria'; para $12,6 \%$ de homens e $11,1 \%$ de mulheres os filhos 'simbolizam o amor dos pais'; para $11,1 \%$ e $7.8 \%$ são fonte de realização pessoal; para $8,8 \%$ vs $7,8 \%$ os filhos são o único amor que dura para sempre; e para $18,7 \%$ dos homens e $9 \%$ das mulheres os filhos 'darão continuidade à família, nome, património' ( $\chi 2=24,49, \mathrm{gl}=10,483, \mathrm{p}<0,01)$. Vanessa Cunha (2005) desenvolve de modo sistemático, no quadro do estudo coordenado por Karin Wall, quatro funções ou dimensões fundamentais dos fi lhos na família: afectiva, expressiva, estatutária e instrumental.

18. Geist (2010) no seu estudo sobre as discrepâncias nas percepções por género relativamente ao volume de trabalho doméstico, tendo por base os dados da International Social Survey Programme (ISSP) confirma a sua hipótese de que as "discrepâncias de género nos relatos sobre trabalho doméstico são maiores quando as disparidades de género na percepção da equidade do trabalho doméstico são maiores" (Geist, 2010: 223).

19. Neste como noutros poucos grupos profi ssionais importa atender aqui ao facto de se encontrarem subrepresentados na amostra, sendo que nestes casos de baixas frequências importa relativizar a análise.

20. Através da análise estatística dos dados verificamos, a respeito, os seguintes valores para cada um dos filhos: $1^{\circ}$ filho $\chi 2=109,36, g l=1,802, p<0,001 ; 2^{\circ}$ fi lho $\chi 2=79,36, g l=1,802, p<0,001 ; 3^{\circ}$ fi lho $\chi 2=34,09, g l=1,802, p<0,001 ;$ e $4^{\circ}$ filho $\chi 2=15,98, g l=1,802, p<0,001 ; 5^{\circ}$ filho $\chi 2=8,32, g l=1,802, p<$ 0,01 .

21. Análise semelhante mas relativa ao cônjuge dá-nos os resultados que se seguem: $1^{\circ}$ filho $\chi 2=$ $112,00, g l=1,802, p<0,001 ; 2^{\circ}$ filho $\chi 2=63,05, g l=1,802, p<0,001$; e $3^{\circ}$ filho $\chi 2=25,23, g l=1,802, p<$ 0,001 . 


\section{ABSTRACTS}

Este texto incide sobre a divisão das tarefas domésticas entre homens e mulheres em união de facto ou casamento heterossexual não só revelando as suas concepções a este respeito como confrontando as representações com as práticas sociais nesta matéria e, mediante este exercício, aferir o grau de discrepância entre as mesmas e, por outro, fazer uma breve revisitação teórica para explicar as representações e as práticas inigualitárias de género na relações conjugais.

Tendo por base dados empíricos obtidos a partir de uma investigação centrada nas (des)igualdades de género, nomeadamente através de entrevistas e de um inquérito a 802 pessoas em Portugal Continental, os resultados recolhidos confirmam conclusões de outros trabalhos nacionais e internacionais. Não obstante, a nível das representações, se esboçar uma tendência no sentido de a partilha das tarefas ser encarada duma forma equitativa, persiste a desigualdade entre homem e mulher em desfavor desta na distribuição das tarefas domésticas e respectivas horas semanais despendidas e, em particular, a discrepância entre representações e práticas analisadas por sexo, grupo profissional e escalão etário. Se entre os grupos profissionais menos qualificados e mais velhos há a assunção de que tais tarefas domésticas são mais próprias das mulheres, entre os mais qualificados e mais jovens é mais acentuada uma visão equitativa quanto à repartição de tarefas, ainda que tal nem sempre se traduza na prática, verificando-se uma tendencial sobrecarga da mulher nas tarefas domésticas e nos cuidados com os filhos e outros dependentes.

This paper focuses on the division of housework between men and women in a heterosexual marriage (or cohabiting), revealing not only its views at this level as confronting the representations with social practices in order to measure the degree of discrepancy between them. The results confirm findings from other national and international researches. At the level of representations there is a tendency towards equal sharing of tasks, but the inequality between man and woman persists, this being unfavourable for her, in the distribution of household chores and their weekly hours spent on them. There is also a discrepancy between representations and practices given the professional and age group. If among the least skilled occupational and older groups there is the assumption that such chores are more typical of women, among the most qualified and younger is sharper vision regarding equitable distribution of tasks. Although, this does not always translate in practice, verifying a trend overload women with housework and caring for children and other dependents. The results confirm findings from other national and international researches. At the level of representations there is a tendency towards equal sharing of tasks, but the inequality between man and woman persists, in her disfavour, in the distribution of household chores and in the amount of weekly hours spent on them. There is also a discrepancy between representations and practices given the professional and age groups. If among the least skilled, and older groups there is the assumption that such household chores are more typical of women, among the most qualified, and younger there is a sharper vision regarding the equitable distribution of tasks. Although, this does not always translate in practice and it is verified a women's overload in household chores and with child and other dependents

Ce texte met l'accent sur la répartition des tâches ménagères entre les hommes et les femmes en concubinage ou mariage hétérosexuel. 
Il révèle leurs représentations sur le sujet et les confronte avec les pratiques sociales respectives et, à partir de cet exercice, évalue le degré de divergence entre les représentations et les pratiques. Le texte discute les différentes perspectives théoriques sur les représentations sociales et leur éventuel écart par rapport aux pratiques sociales et exploite les données empiriques d'une étude sur les (in)égalités de genre. Ces données ont été collectées notamment au moyen d'une enquête réalisée auprès de 802 personnes, au Portugal continental. Les résultats qui ont été obtenus confirment les conclusions d'autres travaux au niveau national et international. Néanmoins, au niveau des représentations, il est esquissé une propension au partage des tâches d'une forme tendanciellement équitable mais l'inégalité entre hommes et femmes persiste au détriment de ces dernières, en ce qui concerne le partage des tâches ménagères et le nombre d'heures accordées à ces tâches. Les inégalités en fonction du sexe, du groupe professionnel et de l'âge sont particulièrement importantes. Si, parmi les groupes professionnels moins qualifiés et les plus âgés, il est assumé que ces tâches doivent être attribuées aux femmes, parmi les plus qualifiés et les plus jeunes, une perspective plus équitable est prédominante, bien que cela ne se traduise pas toujours au niveau des pratiques car il est constaté que les femmes ont tendance à supporter une surcharge en ce qui concerne les tâches ménagères et les soins accordés aux enfants et autres personnes dépendantes.

\section{INDEX}

Palavras-chave: género, família, profissão, desigualdade

Mots-clés: genre, famille, profession, inégalité, Portugal

Keywords: gender, family, inequalities

\section{AUTHORS}

\section{MANUEL CARLOS SILVA}

Sociólogo. Professor no Departamento de Sociologia e Investigador do Centro de Investigação em Ciências Sociais da Universidade do Minho, mcsilva@ics.uminho.pt

\section{ANA REIS JORGE}

Socióloga. Doutoranda e Investigadora do Centro de Investigação em Ciências Sociais da Universidade do Minho, ana.j.mr@gmail.com

\section{ALEKSANDRA QUEIROZ}

Mestre em Cooperação e Políticas Comunitárias e Investigadora Colaboradora do Centro de Investigação em Ciências Sociais da Universidade do Minho, aleksandraqueiroz@gmail.com 